\title{
MULHERES NEGRAS EM CENA
}

\author{
BLACK WOMEN IN SCENE
}

\author{
Cleonice Elias da Silva* \\ Cleonice.silva@uenp.edu.br
}

RESUMO: O presente artigo analisa o curta-metragem Mulheres Negras: Projeto de Mundo (Day Rodrigues; Lucas Ogasawara, 2016) e o longa-metragem Sementes: Mulheres Pretas no Poder (Éthel Oliveira; Júlia Mariano, 2020) ambos documentários. O primeiro filme tem em sua centralidade as narrativas de nove mulheres negras que convergem com discussões importantes dos feminismos negros. Ele contribui com o processo de conscientização referente às realidades das mulheres negras. O outro, por sua vez, traz uma perspectiva nova na cinematografia nacional, ao tratar da participação de mulheres negras na política, e representa um amadurecimento do cinema realizado por cineastas negras. Os dois filmes contribuem com um processo que se posicionam contra a categoria de subalternidade relegada às mulheres negras historicamente.

PALAVRAS-CHAVE: Cineastas negras, Narrativas de mulheres negras, Participação política.

ABSTRACT: This article analyzes the short film Mulheres Negras: Projeto de Mundo (Day Rodrigues; Lucas Ogasawara, 2016) and the feature Sementes: Mulheres Pretas no Poder (Éthel Oliveira; Júlia Mariano, 2020) both documentaries. The first film focuses on the narratives of nine black women that converge with important discussions of black feminism. It contribues to the awareness process regarding the realities of black women. The other, in turn, shows a new perspective in national cinematography when talk about the participation of black women in the politics, and representes a maturation of cinema made by black women filmmakers. Both films contribute to a process that stands against the categoria of subordination relegated to black women historically.

KEYWORDS: Black women filmakers, Black women narratives, Political participation.

\section{Introdução}

Este artigo analisa os filmes Mulheres Negras: Projeto de Mundo (Day Rodrigues; Lucas Ogasawara, 2016) e Sementes: Mulheres Pretas no Poder (Éthel Oliveira; Júlia Mariano, 2020). Essas obras, cada uma com as suas particularidades, contaram com a participação de mulheres negras na direção e têm como centralidade aspectos referentes às experiências de mulheres negras. O primeiro, um curta-metragem, traz depoimentos de mulheres negras que falam de suas vivências e resistências diante do racismo e sexismo atuantes em nossa sociedade. O segundo, um longa-metragem, acompanha as campanhas de candidatas negras aos cargos de deputadas estaduais no Rio de Janeiro e de deputa federal nas eleições de 2018.

A escolha desses dois filmes, tendo em vista que na contemporaneidade há uma produção de filmes dirigidos por cineastas mulheres negras diversa e que está construindo

\footnotetext{
* Doutora em História Social pela Pontifícia Universidade Católica de São Paulo (2020). Professora colaboradora no Colegiado de História da Universidade Estadual do Norte do Paraná (UENP).
} 
uma cinematografia negra ${ }^{1}$ a partir da perspectiva de gênero tal como defendem Edileuza Penha Souza $(2013,2020)$ e Janaina Oliveira $(2016,2019)$, justifica-se pelo fato, de na minha leitura, eles serem complementares, de serem manifestação de um novo campo de representatividade e de narrativas das mulheres negras no audiovisual nacional em curso. Em linhas gerais, Mulheres Negras: Projeto de Mundo nos traz uma discussão sobre os enfrentamentos cotidianos vivenciados pelas mulheres negras no Brasil motivados por questões raciais, sexismo e machismo. Já Sementes: Mulheres Pretas no Poder trata desses aspectos na cena política, evidenciando o protagonismo de mulheres negras nesse âmbito, ocupado majoritariamente por homens brancos. Acredito que as duas obras permitem uma leitura sobre esse processo em curso, que diz respeito às novas narrativas e representatividades no cinema brasileiro referentes às mulheres negras, assim como os espaços que estão sendo ocupados pelas cineastas negras nesse meio.

As minhas reflexões sobre a temática começaram em um trabalho publicado em artigo em março de 2018 e, posteriormente, em um livro publicado no final do mesmo ano (SILVA, 2018a, 2018b). Elas foram desdobramentos de uma pesquisa que desenvolvi sobre as mulheres cineastas. Para a pesquisa e escrita do livro, realizei entrevistas com cineastas mulheres, entre elas, Adélia Sampaio² que começou a ter sua trajetória conhecida a partir de 2016, quando uma entrevista com ela foi publicada no site Blogueiras Negras, realizada por Renata Martins e Juliana Gonçalves. Os desdobramentos dessa entrevista foram significativos, sendo o principal dele, o reconhecimento do trabalho de Adélia Sampaio, o qual mobiliza e inspira uma nova geração de cineastas no Brasil. Um aspecto a ser ressaltado a razão pela qual o trabalho da cineasta permaneceu no anonimato por muitos anos, algo que foi recorrente tratando-se dos trabalhos realizados por mulheres no audiovisual, todavia, quando está em

\footnotetext{
${ }^{1}$ Este ano o streaming da SPCINE disponibilizou uma Coletânea do Audiovisual Negro, composta por 20 filmes selecionados pela Associação dos Profissionais do Audiovisual Negro (APAN), dentre os quais, 11 têm a participação de diretoras mulheres, sendo eles: Caixa D’ Água (Thaís Scabio; Gilberto Caetano, 2013); Corpo Árvore (Ana Caroline Brito, 2018); Dois Pesos (Rejane Neves, 2017); Encruza (Bruna Andrade; Gleyser Ferreira; Maíra Oliveira; Uilton Oliveira, 2018); A Boneca e o Silêncio (Carol Rodrigues, 2015); Enquanto Canto (Sil Azevedo, 2017); Ferradura (Bea Gerolin, 2017); Francisca (Luandeh Chagas; Mariane Duarte, 2018); Por Gerações (Leila Xavier, 2019); Seo Geraldo - Homem de Música e Planta (Keila Serruya, 2020) e Tambores AfroUruguaios (Naouel Laamiri; Rafael Ferreira, 2017) todos são curtas-metragens.

${ }^{2}$ Adélia Sampaio é a primeira mulher negra a dirigir um longa-metragem no Brasil, Amor Maldito, que estreou em 1984. Outras cineastas negras que dirigiram longas-metragens no país são: Sabrina Rosa que dirigiu com Cavi Borges Vamos Fazer um Brinde, de 2011; Viviane Ferreira cujo curta-metragem O Dia de Jerusa (2014) foi adaptado para um longa, Um Dia com Jerusa, finalizado em 2018; Camila de Moraes finalizou em 2017 o documentário O Caso do Homem Errado e Glenda Nicácio que codirigiu com Ary Rosa Café com Canela (2017), Ilha (2018) e Até o Fim (2020).
} 
questão os trabalhos das mulheres negras, a invisibilidade assume maiores dimensões e complexidades.

Atualmente, essa invisibilidade começa a ser rompida, pois diretoras negras e outras profissionais estão atuando no audiovisual nacional, sobretudo na cena mais independente. As pesquisas sobre as especificidades de suas obras e a representação da mulher negra também estão sendo realizadas, contribuindo para um campo de discussões. Entre alguns trabalhos com esse propósito destaco: Ferreira e Souza (2017); Sobrinho (2017); Monteiro e Ferreira (2014); Silva (2016); Sacramento (2017); Viana (2018); Vieira (2018); e as já mencionadas Souza $(2013,2020)$ e Oliveira $(2016,2019)$. O que aproxima esses trabalhos é o fato de contribuírem com o reconhecimento e valorização dos trabalhos de cineastas negras, assim como irem de encontro ao padrão de representatividade que marginalizava e criava estereótipos negativos das mulheres negras.

Nesse sentido, os dois filmes aqui analisados são duas expressões no contexto contemporâneo do cinema brasileiro realizado por diretoras negras. A partir deles, podemos refletir sobre questões de grande urgência no que diz respeito às condições e aos lugares das mulheres negras em nossa sociedade, que não podem ser analisadas sem levar em consideração a intersecção entre gênero, classe e raça.

O primeiro filme analisado é Mulheres Negras: Projeto de Mundo, o qual subsidia discussões importantes trazidas pelos feminismos negros. Em seguida, Sementes: Mulheres Pretas no Poder permite-nos pensar sobre a participação política das mulheres no Brasil. Tal participação, mais do que nunca, assume uma grande importância uma vez que vivenciamos um contexto de retrocessos políticos no qual muitos direitos conquistados passam a ser questionados e desvalorizados pelo governo instituído.

"Mulheres Negras: Projeto de Mundo" e o não silenciamento

bell hooks apresenta uma crítica que não fica restrita à realidade norte-americana no que diz respeito ao feminismo branco não ter considerado as agendas de lutas das mulheres negras. Em suas palavras: “(...) Ninguém se preocupou em discutir a forma sobre a qual o sexismo operava em ambas independentemente e simultaneamente com o racismo na nossa 
opressão" (hooks, 2014, p. 9). ${ }^{3}$ Grada Kilomba expõe que nos discursos feministas ocidentais o conceito dominante de "homem branco heterossexual" cedeu lugar para o de "mulher branca heterossexual", ocorrendo apenas a mudança de uma categoria, da perspectiva do homem para a da mulher, sem alterar a estrutura racial conservadora (KILOMBA, 2019, p. 97). Por essa razão, dentre outras, as narrativas e produção de conhecimentos feitas por mulheres negras sobre suas realidades e outras são de expressiva importância, característica marcante no filme de Day Rodrigues e Lucas Ogasawara.

O filme nos apresenta depoimentos de nove mulheres negras de diferentes atuações profissionais e idades, são elas: Aldenir Dida Dias, feminista socialista e doutora em Ciências Sociais; Ana Paula Correia, feminista negra, mestra em Ciência Sociais e coordenadora do Centro de Defesa e Convivência da Mulher Casa Anastácia; Andréia Alves ${ }^{4}$, bailarina e integrante do grupo Ilú Oba de Min; Djamila Ribeiro, feminista negra, mestra em Filosofia Política, foi Secretaria Adjunta da Secretaria Municipal de Direitos Humanos e Cidadania de São Paulo, é professora na Pontifícia Universidade Católica de São Paulo, autora de livros sobre racismo e feminismo negro, os quais têm uma boa repercussão no Brasil; Francinete Loiola, revendedora Natura e mãe; Luana Hansen, DJ, MC e produtora musical; Monique Evelle, comunicadora e fundadora do Desabafo Social; Preta-Rara, rapper, professora de História e criadora da campanha \#euempregadadoméstica e Nenesurreal, grafiteira, educadora social e avó.

A obra aposta na linguagem clássica da produção de documentários, sendo o seu cerne os depoimentos das mulheres, mas vai além desse modelo com as inserções das cenas de Andréia dançando à noite em uma praia, o que proporciona ao curta-metragem um dinamismo, não ficando restrito aos depoimentos. Todavia, ele não é marcado por experimentações estéticas e de cunho narrativo, o que não desqualifica o seu conjunto. Com sua linguagem objetiva, traz um resumo de questões importantes para a discussão sobre as realidades e os problemas enfrentados pelas mulheres negras no Brasil.

\footnotetext{
${ }^{3}$ Cito a tradução livre do livro Ain't I a Women: Black Women and feminism, cuja primeira data de publicação é o ano 1981, feita pela Plataforma Gueto em janeiro de 2014.

${ }^{4}$ As aparições de Andréia no filme são realizadas através de takes nos quais ela aparece dançando, diferente das demais mulheres mencionadas, ela não dá um depoimento falado, mas está presente no filme através da dança negra marcada por uma tradição da ancestralidade africana.
} 
Ele está organizado em 8 blocos, que nomeio aqui de capítulos, são eles: Essa narrativa existe; O fim da história única; Juventude; Preta Rara, Espelho: tornar-se negra; Interseccionalidade; Em todos os lugares; São muitas narrativas. Grosso modo, é possível afirmar que o filme traz discussões caras aos feminismos negros, as quais assumem um caráter particular pois são expressões de subjetividades e experiências de diferentes mulheres negras que dão seus depoimentos no filme. Outro aspecto a ser mencionado é o lugar que a narrativa cumpre nesse filme, ou seja, as narrativas das mulheres negras têm que estar na esfera pública da sociedade, sendo elas mesmas as produtoras e porta-vozes de suas vivências. Nesse sentido, o prólogo do filme é a fala de Djamila Ribeiro que menciona o privilégio de quem sempre teve a fala e a importância de se colocar em um lugar de escuta para ouvir os que foram silenciados.

Por mais que os problemas enfrentados pelas mulheres negras estejam nos depoimentos das mulheres, a essência do filme são as resistências dessas mulheres e as formas como buscam superar e enfrentar a nocividade do racismo e sexismo em suas experiências cotidianas. As falas seguintes a de Djamila na abertura do filme são de Preta Rara, que afirma: "O corpo da mulher negra sempre foi mercadoria". Dida complementa afirmando que a classe trabalhadora é marcada pela raça e que as mulheres negras são a base da pirâmide social. Nenesurreal fala de uma resistência movida pelo amor: "A gente sangra todos os dias!". Ana Paula afirma que as mulheres da periferia sempre encontraram resistências e modos de sobrevivência: "Somos nós mesmas que estamos brigando com as políticas públicas". Ela menciona a sua luta para que existam lugares para as narrativas das mulheres negras, para que tenham visibilidade. Mais uma vez o depoimento de Djamila é contundente contra um silenciamento imposto por anos às mulheres negras: "Não quero ser objeto de pesquisa, quero ser o sujeito, quero estar nos lugares que foram negados. A gente não vai ficar mais quieta, nem que a gente vá para o embate".

É a sua fala que abre o primeiro capítulo do filme, Essa narrativa existe, a filósofa chama a atenção para a importância de se falar em primeira pessoa: “(...) A gente sempre foi muito colocada como objeto de estudo, ou como pessoas que não produzem conhecimento, que não produzem literatura e o quanto isso prejudica a nossa formação como sujeito, na formação de nossa subjetividade". 
A problemática do silenciamento vivenciado pelas mulheres negras e apontada no documentário é ressaltada por bell hooks:

[...] O nosso silêncio não era meramente uma reação contra as mulheres brancas liberacionistas ou um gesto de solidariedade para com os homens negros patriarcais. Era o silêncio dos oprimidos - o profundo silêncio causado pela resignação e aceitação de um único destino. As mulheres negras contemporâneas não se podiam juntar para lutar pelos direitos das mulheres porque nós são víamos a "natureza feminina" como um aspecto importante de nossa identidade (HOOKS, 2014, p. 5).

Djamila completa afirmando que não se deve aceitar que só contem histórias sobre as mulheres negras, que é preciso ir contra uma narrativa imposta e disputar narrativas e falar a partir de suas perspectivas, contar novas histórias, dar espaço para uma multiplicidade de vozes, "romper como essa voz única", pois "o disputar narrativa é essencial”. Nesse sentido, Lélia Gonzalez defendia a necessidade de um aprofundamento das reflexões enquanto mulheres negras (GONZALEZ, 1984, p. 225).

As reflexões produzidas pelas mulheres negras são as que mais conseguem dimensionar os impactos das diferentes opressões em suas vidas tanto no que diz respeito a uma esfera privada quanto à pública. Essas opressões manifestam questões de raça, classe e gênero, daí a importância de trabalhos como de bell hooks, Patricia Hill Collins, Angela Davis, Lélia Gonzalez, Beatriz Nascimento, Sueli Carneiro, Djamila Ribeiro, entre outras. Os trabalhos de teóricas feministas negras são ressaltados por Grada Kilomba:

A reivindicação de feministas negras ${ }^{5}$ não é classificar as estruturas de opressão de tal forma que mulheres negras tenham que escolher entre a solidariedade com homens negros ou mulheres brancas, entre "raça" ou gênero, mas ao contrário, é tornar a realidade e experiência visíveis tanto na teoria quanto na história. O movimento e a teoria de mulheres negras têm tido, nesse sentido, um papel central no desenvolvimento de uma crítica pósmoderna, oferecendo uma nova perspectiva de debates contemporâneos sobre gênero e pós-colonialismo (KILOMBA, 2019, p. 108).

Monique fala das narrativas que ouvia quando criança através das histórias contadas pela sua mãe, que tinham princesas parecidas com ela, negras e de cabelos crespos. $^{6}$

\footnotetext{
${ }^{5}$ Os grifos são da autora.

${ }^{6} \mathrm{O}$ cabelo é um elemento importante no processo de construção/aceitação identitárias das mulheres negras. A cineasta carioca Yasmin Thayná trata esse aspecto em seu filme Kbela (2015). Grada Kilomba afirma que os cabelos das mulheres negras e homens negros são instrumentos importantes de consciência entre as africanas e os africanos da diáspora: "[...] Nesse contexto, o cabelo tornou-se o instrumento mais importante da consciência política entre africanas/os e africanas/os da diáspora. Dreadlocks, rasta, cabelos crespos ou "black" e penteados africanos transmitem uma mensagem política de fortalecimento racial e um protesto contra a
} 
Entretanto, teve que lidar com o choque ao se deparar com um mundo trazido pela televisão que não era representativo de nossa realidade étnico-racial. As identidades negras no Brasil sempre foram reivindicadas pelos movimentos negros, a sua dimensão subjetiva está atrelada a uma dimensão política, que tem como manifestação as lutas diversas da população negra.

No quarto capítulo, que leva o seu nome, Preta Rara fala das dificuldades que vivenciou quando procurava emprego. Ela diz que mesmo tendo feito curso para secretária, não conseguiu emprego nessa área. Então, diante disso, passou a entregar currículos sem foto, e começou a ser chamada para entrevistas, mas não passava. Atribui isso ao fato de ser mulher, preta e gorda. Preta Rara enfatiza que o único caminho para mulher negra não pode ser apenas o de empregada doméstica: "Minha bisavó foi escrava, minha avó foi empregada doméstica, minha mãe foi empregada doméstica". Ela relata no filme uma situação ofensiva que passou com um patrão, uma dentre muitas outras que marcam os trabalhos das empregadas domésticas em nosso país.

Não desqualificando o trabalho digno realizado pelas empregadas domésticas e o papel que cumprem dentro de muitas famílias, além de suas próprias, é possível afirmar que o fato de a maioria das empregadas domésticas no Brasil serem negras corresponde a um legado do sistema escravista, o qual explorou homens e mulheres negras, sendo que estas vivenciaram uma exploração com maiores proporções. Afirmativa que vai ao encontro do que é defendido por bell hooks:

[...] O homem negro foi inicialmente explorado como um trabalhador dos campos, a mulher foi explorada como uma trabalhadora dos campos, uma trabalhadora das tarefas domésticas, uma criadora de animais e como um objeto de assaltos sexuais dos homens brancos (hooks, 2014, p. 18).

As noções que circulam na sociedade sobre a mulata, a doméstica e a mãe preta têm relação com o passado da escravidão. Além disso, são influenciadas diretamente pelas articulações entre racismo e sexismo, as quais produzem "efeitos violentos sobre a mulher negra em particular" (GONZALEZ, 1984, p. 224). ${ }^{7}$

opressão racial. Eles são políticos e moldam as posições de mulheres negras em relação a "raça", gênero e beleza. Em outras palavras, eles revelam como negociamos políticas de identidade e racismo - pergunte a Angela Davis! (KILOMBA, 2019, p. 127).

${ }^{7}$ É importante mencionar que talvez Lélia Gonzalez seja a primeira intelectual negra no Brasil que defendeu uma abordagem analítica que articulasse as relações raciais, de gênero e classe (ARAÚJO, 2020). 
No capítulo cinco, Espelho tornar-se negra, as entrevistadas falam sobre o autorreconhecimento como mulheres negras, e como esse ato foi um ponto de inflexão em suas vidas. Francinete fala emocionada dos racismos que sofre. Dida confessa que, apesar de na época de realização do filme ter 50 anos, reconheceu-se como mulher negra há cerca de 20, ou talvez menos. Monique reafirma que não é uma mulher morena, e sim negra. Ana Paula enfatiza o significado de entender sua estrutura, de olhar para si mesma, para, assim, romper com uma vida apagada. Para Djamila, o amor é um ato de resistência: “(...) quando a gente se ama, a gente vai olhar o mundo de outra forma, e vai reconfigurar as relações ao nosso redor de outra forma". Os relatos dessas mulheres levam-nos a perceber como o racismo e sexismo afetam diretamente as subjetividades, e o reconhecer-se como mulher negra é um processo fundamental para a superação de alguns dos efeitos nocivos da junção dessas duas formas de opressão e discriminação.

No penúltimo capítulo do filme, Em todos os lugares, Dida fala sobre sua experiência quando pensou em fazer doutorado na USP, e disseram-lhe que lá as negras e os negros não sobrevivem. Ela relata como hoje fica feliz em ver a juventude negra ingressando nessa universidade, e afirma convicta: "O Estado brasileiro nos deve isso". Cabe mencionar a importância na realidade brasileira de políticas de cunho afirmativo que visam dar condições para que a população negra ingresse nas universidades, sendo elas apenas um dos espaços, que por muito tempo foi relegado a ela, que devem ser ocupados.

Por fim, o último capítulo, São muitas narrativas, retoma a reflexão sobre as narrativas das mulheres negras. Ana Paula fala a respeito da importância de se reconhecer o valor das mulheres negras e de as meninas terem referências para se verem de outra forma. Monique destaca que o embate é permanente, ao afirmar que não dá para ter paciência, diz que tenta escutar por acreditar no diálogo, mas que por dentro está para explodir. Nenesurreal faz menção às brigas diárias que precisa travar. Djamila afirma que é necessária uma reconfiguração epistemológica a partir das perspectivas das mulheres negras. Luana, por sua vez, fala das limitações da Lei Maria da Penha, chamando a atenção para importância do respeito para se ter um lugar melhor para viver. No epílogo do filme, Preta Rara recita um poema que fala das lutas e resistências das mulheres negras.

Conforme já mencionado, a partir dos depoimentos das mulheres entrevistadas no filme, é possível perceber questões evidentes pautadas nas reivindicações dos feminismos 
negros. Um aspecto a ser destacado é como essas questões se aproximam das realidades de muitas mulheres negras, sobretudo as das classes sociais mais pobres. Todavia, há de se considerar que possivelmente elas não alcancem a todas nas mesmas proporções. Em outras palavras, as discussões e reivindicações dos feminismos negros precisam ser conhecidas principalmente pelas mulheres mais pobres de nossa sociedade, para que as lutas não fiquem restritas a grupos seletos de militantes e intelectuais. O processo de conscientização é permanente e o filme em questão contribui de alguma forma com ele por ter uma linguagem clara e objetiva, cumprindo, no meu ponto de vista, um papel importante ao falar das realidades das mulheres negras.

"Sementes: Mulheres Pretas no Poder": a participação política de mulheres negras no Brasil

O documentário Sementes: Mulheres Pretas no Poder dirigido por Éthel Oliveira e Júlia Mariano ${ }^{8}$, estreou no YouTube em 7 de setembro deste ano de 2020, no canal da distribuidora Embaúba Filmes, ficou disponível até o dia 30 do referido mês. Na metade do dia 28, ele tinha 33. 567 visualizações, ou seja, apesar das consequências negativas da pandemia de Covid-19 para a cultura de forma geral, o filme teve uma bom alcance e repercussão.

Em linhas gerais, o longa-metragem nos traz momentos das campanhas de seis mulheres negras no Rio de Janeiro nas eleições de 2018. Jaqueline Jesus, Mônica Francisco, Renata Souza, Rose Cipriano, Tainá de Paula foram candidatas a deputadas estudais, e Talíria Petrone a deputada federal. Entre elas, se elegeram Mônica Francisco, Renata Souza e Talíria Petrone. Nas eleições de 2018, 4.398 mulheres negras se candidatam, e as candidaturas autodeclaradas negras representaram um aumento de 93\% em comparação as eleições de 2014. Sementes, entre outros, assume o propósito de falar sobre o legado de Marielle Franco na política nacional, a vereadora do PSOL e seu motorista Anderson Pedro Gomes foram assassinados em 14 de março de 2018.

A primeira etapa das filmagens do documentário foi viabilizada por um financiamento coletivo que arrecadou 50 mil reais, depois o projeto conseguiu um apoio da Open Society Fund de 35 mil dólares (que na época foram cerca de 120 mil reais), além disso, foram capitados 40 mil reais via ISS e 10 mil da produtora Noix, de Júlia Mariano. Esta afirma que a

\footnotetext{
8 Júlia Mariano também foi responsável pela produção executiva do filme.
} 
ideia do filme foi de Helena Dias, que co-assina o argumento e o roteiro, que se interessou, em julho de 2018, pelo aumento de pré-candidaturas de mulheres negras, e sugeriu que elas fossem atrás de algumas dessas candidatas e filmassem suas campanhas para entender essa nova situação (PÉCORA, 2020).

As filmagens de momentos das campanhas das candidatas foram realizadas por diferentes equipes. ${ }^{9}$ Sobre esse processo a cineasta Éthel Oliveira comenta:

[...] Era preciso comprometimento estético e respeito absoluto às orientações da direção: não fazer entrevistas, ficar a uma distância justa da imagem, evitar zoom, buscar planos que acompanhassem as pessoas. E tinha uma questão de afeto mesmo, no sentido de que a gente estava registrando um momento dramático da democracia brasileira pela perspectiva das mulheres pretas. Até onde a gente sabe, isso era algo que ninguém estava fazendo. [...] (PÉCORA, 2020)

O filme de Éthel Oliveira e Júlia Mariano, no seu conjunto, também tem uma linguagem clara e objetiva, e corresponde a um projeto inovador, sobretudo, pela temática abordada no que diz respeito à atuação de mulheres negras na esfera política do país. Aspecto afirmado por Éthel Oliveira ao dizer que Sementes tem como centralidade o "fazer político das mulheres pretas", uma vez que, segundo ela, essa imagem não existe, não há registros, por exemplo, da campanha de Lélia Gonzalez, candidata à deputada federal em 1982 e à deputada estadual pelo Rio de Janeiro em 1986 (PÉCORA, 2020). A cineasta complementa:

[...] Eu desconheço imagens da campanha de Leci (Brandão, eleita deputada estadual por São Paulo em 2014 e reeleita em 2018), do próprio Abdias (do Nascimento, deputado federal de 1983 a 1987 e senador de 1997 a 1999) ou de reuniões do movimento negro para pensar as políticas de cotas nas universidades. A imagem do fazer político do povo preto não existe e era esse papo que a gente tinha com a equipe. [...] (PÉCORA, 2020).

O filme é iniciado mostrando a comoção e indignação que o assassinato de Marielle Franco gerou, e como o fato levou muitas mulheres negras ingressarem na política sendo a vereadora uma grande inspiração. O filme fala de um legado deixado por ela para política nacional e tem a pretensão que sua figura e história sejam conhecidas pelo mundo, de acordo com o afirmado por Éthel Oliveira:

A gente quer colaborar para que a Marielle esteja no panteão internacional dos ativistas negros. (Então pensávamos) Se essa obra pode ser bem acabada, e assim potencializar o interesse do espectador pela luta das mulheres pretas, vamos com tudo. Vamos jogar arte, vamos jogar trilha,

\footnotetext{
9 Segundo as diretoras, houve a preocupação de montar uma equipe com a participação de profissionais mulheres negras, assim como dar oportunidades para as que estão iniciando suas carreiras (PÉCORA, 2020).
} 
vamos trazer duas excelentes montadoras (Mariana Penedo e Gabriela Paschoal). E assim foi (PÉCORA, 2020).

A versão do filme disponibilizada no canal do Youtube já tinha legendas em inglês. Sementes é um documentário com uma montagem bem feita e as cineastas conseguiram dar uma unidade estética e narrativa, apesar de as imagens terem sido captadas por diferentes equipes.

As filmagens datam de maio de 2018 a fevereiro de 2019, o período de campanha e os eventos de posse das candidatas eleitas, respectivamente. Mônica Francisco, em uma das cenas iniciais do filme, fala das dificuldades encontradas pelas mulheres negras de terem acesso a direitos básicos como água potável, mobilidade, saúde, educação, entre outros. A equipe de filmagem acompanha um culto de Mônica realizado em local do Centro do Rio de Janeiro. A candidata que conhecemos em seguida é Tainá de Paula no momento de lançamento de sua campanha, denominada como Ocupação política e as pretas no poder, Tainá é arquiteta e urbanista, em sua fala, pergunta ao público quantas arquitetas e urbanistas negras que conhecem, ela responde dizendo que conhece pouquíssimas.

A predominância das cenas são em externas, entre os eventos presentes no filme está a 4ạ Marcha das Mulheres Negras, ocorrida no bairro de Copacabana em 2018, as câmeras que acompanharam o evento são atentas aos detalhes, destacando os momentos de falas das candidatas que o filme acompanha.

Em agosto do referido ano, Talíria Petrone teve problemas com um policial em um evento de sua campanha. Neste ano de 2020, já empossada no seu cargo de deputada federal, Talíria recebeu novas ameaças, as quais ela sofre deste da época de sua candidatura à vereadora em Niterói. ${ }^{10}$

Em Duque de Caxias, na Baixada Fluminense, acompanhamos a candidata Rose Cipriano, educadora, ativista do Coletivo Minas da Baixada e Militante do MNU, nas ruas fazendo sua campanha e panfletagem. Rose foi professora da rede estadual do Rio de Janeiro, atualmente trabalha na rede municipal de Duque de Caxias. Ela fala de seu trabalho com as classes populares, e sobre a desvalorização dos profissionais da educação e sucateamento da mesma. É importante mencionar que as campanhas das seis mulheres assumem

\footnotetext{
${ }^{10}$ Além de Talíria Petrone, outras mulheres negras envolvidas com a política estão sofrendo ameaças, entre elas, Benny Briolly, Renata Souza e Tamires Sampaio (FERREIRA, 2020).
} 
particularidades, que resumo no fato de algumas delas terem um pouco mais de recursos para as viabilizarem dos que outras.

A equipe de filmagem acompanha a candidata Jacqueline de Jesus, professora de psicologia no Instituto Federal do Rio de Janeiro, em sua casa se arrumando para um evento, a única cena deste tipo no filme. Ela chama a atenção para a problemática da transfobia, e para o fato de que os lugares da política precisam ser ocupados pelas mulheres negras e pela população trans.

Luis Felipe Miguel menciona que o campo político tem como característica a predominância masculina, e que ele não é convidativo à participação das mulheres. Diante dessa realidade, não basta apenas a execução de políticas e práticas que superem as barreiras contra a inclusão concedendo o direito ao voto ou outros com pretensões igualitárias, faz necessário que os grupos marginalizados sejam incorporados ao corpo político. O autor apresenta tal assertiva embasado em uma premissa de Anne Phillips (MIGUEL, 2014, p. 94). Conforme foi possível perceber, essa questão está no cerne de Sementes.

Uma discussão sobre quais grupos de sociedade devem ser beneficiados por políticas afirmativas deve ser considerada. Não apenas mulheres têm o direito de ocupar cargos políticos, mas também trabalhadores, indígenas, homossexuais, pessoas trans, com deficiência, grupos religiosos minoritários, entre outros. Esses grupos sofreram e sofrem historicamente processos de exclusão e continuam distantes da participação no contexto político (MIGUEL, 2014, p. 99).

Em outro momento que nos são apresentadas cenas de Renata Souza, jornalista e doutora em Comunicação e Cultura, em ações da sua campanha, ela conversa com estudantes da Universidade Federal do Rio de Janeiro e fala às jovens e aos jovens da importância de mulheres negras serem eleitas e das possibilidades que podem surgir quando elas ocuparem cargos na Alerj e na Câmara Federal.

Mônica, em um evento realizado na Lapa, afirma que é uma ousadia e desafio uma mulher como ela ascender às instâncias políticas, e esse processo não é uma luta individual. Em outra cena, Rose Cipriano participa de uma roda de conversa em Nova Iguaçu, surge a discussão de que mulheres não votam em mulheres. Rose fala sobre a necessidade de os 
partidos políticos viabilizarem as candidaturas de mulheres. ${ }^{11} \mathrm{Um}$ ponto importante mencionado por ela são as diferentes agendas que podem ser assumidas pelas mulheres na política, e como esta tem que ser diversa, e critica um aspecto marcante da política nacional que diz respeito a algumas famílias que ocupam cargos políticos há anos, ela conclui dizendo que: “A gente ainda não aprendeu a voltar em gente como a gente .

Embora a inserção das mulheres na política seja uma das lutas dos femininos, ela não garante que todas elas tenham identificação com as agendas de gênero e assumam esses propósitos em suas pautas de governo. Nesse sentido, Luis Felipe Miguel ressalta que,

Outro problema relevante é o "essencialismo" potencial subjacente. Fica implícito que as mulheres, apenas por serem mulheres, responderão a interesses idênticos. No entanto, os indivíduos ocupam simultaneamente diversas "posições de sujeito", cujas pressões são variadas, e, muitas vezes, contraditórias. Por exemplo, uma mulher negra, trabalhadora manual, evangélica, consumidora de determinados bens e moradora da periferia pode ter interesses conflitantes associados a cada uma dessas características. Integrar um grupo não significa expressar suas demandas. Muitas mulheres candidatas e eleitas não apresentam comprometimento com as questões de gênero. $\mathrm{E}$, de maneira mais profunda, é questionável mesmo a noção de que existem interesses objetivamente identificáveis, ligados às posições sociais. Mulheres podem discordar, e de fato discordam, sobre quais são ou quais medidas políticas devem apoiar (MIGUEL, 2014, p. 99-100).

Tainá de Paula, em um evento de sua candidatura, fala sobre a importância de construção de uma mobilização antifascista, que possibilite não apenas o debate sobre a diversidade, mas também sobre a sobrevivência das populações marginalizadas. Esta fala da candidata surgiu em uma discussão sobre a crescente onda de conservadorismo, tendo a figura de Jair Bolsonaro com principal emblema. As candidatas participaram das manifestações do Ele Não, uma semana antes das eleições de 2018. A referida mobilização

\footnotetext{
${ }^{11} \mathrm{Em}$ 2018, foi decidido pela Justiça Eleitoral que os partidos políticos deveriam reservar pelo menos $30 \%$ de suas verbas e vagas para candidaturas de mulheres. Entretanto, os números do Tribunal Superior Eleitoral (TSE) demonstram um cenário pouco promissor tratando-se da igualdade de gênero, tendo em vista que as candidaturas de mulheres à prefeitura nas eleições deste ano de 2020 teve o aumento de apenas 0,1\%, em relação às eleições de 2016. O aumento também não foi expressivo para as candidaturas à vereadora, representando $1,3 \%$. Ocorreu um aumento na candidatura de negros aos cargos de prefeito e vereador, no total de 270 mil candidatos, um aumento de 2,08\% em comparação à 2016. O número de candidatos negros (50\%) nas eleições de 2020 é maior do que de brancos (48\%). Em 2016, os candidatos brancos representavam uma porcentagem de $51,5 \%$. O maior número de mulheres negras candidatas é o da região norte, sendo elas $76 \%$, seguido pelo nordeste, com $68 \%$. As candidaturas às prefeituras de mulheres correspondem à $13 \%$ e dos homens à $87 \%$. O número de mulheres candidatas a vereadoras é maior, 34\%, e de homens é de 66\% (MARTINS, 2020).
} 
teve na sua linha de frente as mulheres que se posicionaram contra os retrocessos políticos que a candidatura de Bolsonaro representava.

Nas cenas finais do filme, são acompanhados os resultados das eleições, e os eventos de posse das candidatas eleitas. As candidatas não eleitas foram Rose Cipriano que conseguiu 17.483 votos; Tainá de Paula 8.653 e Jacqueline de Jesus 2.271. Renata Souza foi eleita com 63.937 votos; Mônica Francisco com 40.631 e Talíria Petrone com 107.317. Renata fala que ela e outras candidatas negras fazem parte de um processo de vanguarda muito interessante, que mostra como a política tem que ter mais a cara do povo, que tem que se relacionar com as experiências cotidianas, de Estado e de cidade, experimentando a partir de um ponto de vista marcado "pela dor na carne".

O filme Sementes: Mulheres Pretas no Poder cumpre um papel expressivo em nossa contemporaneidade, tendo em vista seus aspectos mencionados no decorrer deste texto. Acredito que seja uma obra divisora de águas na cinematografia realizada por mulheres negras e sobre elas. O filme assume um posicionamento contra o racismo e o sexismo, ao apresentar um contexto de alternativas na esfera conservadora na política nacional. Nessa direção, Júlia Mariano afirma que Sementes representa uma obra que traz à tona outras experiências e possibilidades de cinema e de narrativas.

Uma coisa é ter o discurso antirracista e outra coisa é ter uma vida antirracista nas suas ações diárias. $O$ que a gente está fazendo aqui é abrir para o novo, para outras experiências, para outras possibilidades de cinema e de narrativas. Se quem detém os meios de produção não começa a fazer isso, quem vai fazer? Se é para fazer reparação histórica, quem está montado na herança tem de se desmontar (PÉCORA, 2020).

A particularidade do filme é mostrar as possibilidades de atuação política de mulheres negras, rompendo com os privilégios de classe e raça que também se fazem presentes nas relações entre as mulheres. Entretanto, é importante mencionar que as condições existentes ainda dificultam muito o acesso das mulheres aos cargos públicos, e devemos continuar reivindicando medidas que possam modificar esse cenário, conforme defende Luis Felipe Miguel:

[...] Os dados de diversos países revelam que, entre ocupantes de cargos públicos, o percentual de viúvas e solteiras é muito maior que o de viúvos e solteiros. A família, que para eles pode representar uma retaguarda de apoio à carreira, para elas conta como um fardo. Em outras palavras: mecanismos de incentivo à participação política podem ser meritórios, mas as condições para o exercício paritário do poder dependem ainda de medidas como 
creches, divisão das tarefas domésticas e fim da discriminação de gênero no mercado de trabalho (MIGUEL, 2014, p. 106).

\section{Considerações finais}

Os dois filmes considerados neste artigo rompem com um paradigma de lugar de subalternidade das mulheres negras na realidade sociopolítica brasileira, contudo, cabe enfatizar que muitas ainda têm suas vivências afetadas por essa condição. Gayatri Chakravorty Spivak, em um trabalho pioneiro para os estudos pós-coloniais, pergunta se pode o subalterno falar e constata que a condição subalterna da mulher é uma problemática mais evidente do que a dos homens, tendo em vista as condições sociais de mulheres pobres, negras que imprimem novos especificidades do ser subalterna, situação que caracteriza as realidades póscoloniais (SPIVAK, 2010, p. 85).

A dominação masculina faz com que a posição das mulheres na sociedade não seja unicamente de "diferente" da dos homens. O lugar social das mulheres tem como característica a subalternidade, uma vez que têm menos acesso a cargos políticos, entre outros. Nós estamos mais sujeitas a sermos vítimas de violência e humilhações diversas. Para o rompimento com essa condição, faz-se necessária "a revisão dos privilégios masculinos", mesmo muitos homens dando apoio às lutas das mulheres (MIGUEL, 2014, p. 102).

bell hooks tem uma premissa de que a margem pode ser um "espaço de abertura radical" (hooks, 1989, p. 149 apud KILOMBA, 2019, p. 68) propício à criatividade e aos novos discursos críticos. Grada Kilomba esclarece que considerar a margem como um lugar potencializador das criatividades pode gerar um efeito que romantiza a opressão, e apresenta o questionamento de que até que ponto nós idealizamos as posições periféricas e com isso minamos a violência do centro. Todavia, a autora afirma, que de acordo com o defendido por bell hooks, essa não é uma perspectiva romântica, mas o "reconhecimento da margem como uma posição complexa que incorpora mais de um local". A margem constitui-se como um lugar de repressão e também como de resistência. ${ }^{12} \mathrm{Em}$ situações de opressão, esses dois locais estão presentes, pois “a opressão forma as condições de resistência” (KILOMBA, 2019, p. 68-69).

\footnotetext{
12 Grada Kilomba inspira-se nas reflexões de bell hooks (1990).
} 
Os filmes Mulheres Negras: Projeto de Mundo e Sementes: Mulheres Pretas no Poder podem ser lidos como formas de resistência, tanto no que diz respeito ao seu modo de produção, ou seja, obras dirigidas por mulheres negras quanto às temáticas que reverberam na esfera pública. Sendo Sementes um filme mais complexo que alude a um amadurecimento da cinematografia realizada por mulheres negras e que as tem como centralidade. Como bem afirma Júlia Mariano, é um filme que demonstra as possibilidades para o cinema nacional, entretanto, ainda é preciso criar condições para que mais cineastas negras mulheres consigam realizar seus filmes e que eles tenham visibilidade. No cenário político, essa questão também está posta, tendo vista que o número de mulheres negras e brancas em cargos políticos ainda é muito pequeno. A inserção de mulheres na política e no audiovisual pode contribuir para uma melhor representatividade da nossa sociedade, e possibilitar que demais grupos marginalizados ascendam a tais posições. Para que assim, as mulheres negras e demais grupos marginalizados tornem-se sujeitos de suas narrativas e lutas políticas.

Todo o processo alcança um estado de descolonização; isto é, internamente, não se existe mais como a/o "Outra/o", mas como o eu. Somos eu, somo sujeito, somos quem descreve, somos quem narra, somos autoras/es e autoridade de nossa própria realidade. Assim, regresso ao início deste livro: tornamo-nos sujeito (KILOMBA, 2019, p. 238).

\section{REFERÊNCIAS BIBLIOGRÁFICAS}

ARAÚJO, Barbara. Lélia Gonzalez, intérprete do capitalismo brasileiro. Jacobin Brasil, 13 de setembro de 2020. Disponível em: <https://jacobin.com.br/2020/09/lelia-gonzalez-interprete-do-capitalismobrasileiro/>. Acesso em: 13 set. 2020.

FERREIRA, Ceiça. SOUZA, Edileuza. Penha. Formas de visibilidade e (re)existência no cinema de mulheres negras. In: HOLANDA, Karla. TEDESCO Mariana Cavalcanti (Orgs.). Feminino e plural: Mulheres no cinema brasileiro. Campinas, SP: Papirus, 2017. p. 175-186.

ERREIRA, Lola. Mulheres negras são alvos de violência política em ano eleitoral e buscam soluções para ataques cada vez mais sofisticados. Gênero e Número, 27 de agosto de 2020. Disponível em: <http://www.generonumero.media/violencia-politica-mulheres-negras/>. Acesso em: 29 set. 2020.

GONZALEZ, Lélia. Racismo e Sexismo na cultura brasileira. Revista de Ciências Sociais Hoje, ANPOCS, 1984, p. 223-244.

HOOKS, bell. Não sou eu uma mulher: mulheres negras e feminismo. Plataforma Gueto, 2014.

MARTINS, Flávia Bozza; BRUNO, Maria Martha; FERRARI, Marília. Eleições 2020: número de candidatas tem aumento tímido, mas candidaturas negras são maioria. Gênero e Número, 27 de setembro de 2020. Disponível em: http://www.generonumero.media/eleicoes-2020-candidaturas-negrasmaioria/. Acesso em: 28 set. 2020. 
MIGUEL, Luis Felipe. Gênero e representação política. In: MIGUEL, Luis Felipe; BIROLI, Flávia. Feminismo e política: uma introdução. São Paulo: Boitempo, 2014. p. 93-107.

MONTORO, Tania; FERREIRA, Ceiça. Gênero e Raça: um mergulho nos estudos de comunicação e recepção. ANIMUS - Revista de Comunicação Midiática, Santa Maria, v. 13, n.24, p.1-22, 2014.

OLIVEIRA, Janaína. Por um cinema negro no feminino. In: LUSVARGHI, Luiza; SILVA, Camila Vieira da. (Orgs.). Mulheres atrás das câmeras: As cineastas brasileiras de 1930 a 2018. São Paulo: Estação Liberdade, 2019. p. 38-49.

OLIVEIRA, Janaína. Kbela e Cinzas: O cinema negro no feminino do Dogma Feijoada aos dias de hoje. In: Avanca Cinema International Conference. Avanca: Edições Cine-Clube de Avanca, 2016.

PÉCORA, Luísa. Com "Sementes", diretoras destacam mulheres negras na política e no cinema. Mulher no Cinema, 25 de setembro de 2020. Disponível em: < https://mulhernocinema.com/destaques/comsementes-diretoras-destacam-luta-das-mulheres-negras-na-politica-e-no-cinema/>. Acesso em: 26 set. 2020.

SACRAMENTO, Evelyn dos Santos. Adélia Sampaio: uma cineasta que ousou ser. Seminário Internacional Fazendo Gênero 11 \& 13th Women's Worlds Congress (Anais Eletrônicos), Florianópolis, 2017, p. 1-10.

SILVA, Cleonice Elias da Silva. Mulheres negra no audiovisual brasileiro. Revista Doc On-line, n.23, março de 2018a.

SILVA, Cleonice Elias da Silva. Cineastas Mulheres: um panorama histórico. São Paulo: Liber Ars, 2018b.

SILVA, Conceição de Maria Ferreira. Mulheres negras e (in)visibilidade: imaginários sobre a intersecção de raça e gênero no cinema brasileiro (1999-2009). 2016. 297f. Tese (Doutorado em Comunicação Social) - Faculdade de Comunicação, Universidade de Brasília, Brasília, 2016.

SOBRINHO, Gilberto Alexandre. Identidade, resistência e poder: mulheres negras e a realização de documentários. HOLANDA, Karla. TEDESCO Mariana Cavalcanti (Orgs.). Feminino e plural: Mulheres no cinema brasileiro. Campinas, SP: Papirus, 2017. p. 163-174.

SOUZA, Edileuza Penha de. Mulheres negras na construção de um cinema negro no feminino. Aniki: Revista Portuguesa da Imagem em Movimento, v.7, n.1 p. 171-188, 2020.

SOUZA, Edileuza Penha de. Cinema na panela de barro: mulheres negras, narrativas de amor, afeto e identidade. 2013. 260f. Tese (Doutorado em Educação) - Faculdade de Educação, Universidade de Brasília, Brasília, 2013.

SPIVAK, Gayatri Chakravorty. Pode o subalterno falar? Tradução de Sandra Regina Goulart; Marco Pereira Feitosa; André Pereira Feitosa. Belo Horizonte: Editora UFMG, 2010.

VIANA, lara Félix Pires. "Cineastas negras: trajetórias socioespaciais e narrativas cinematográficas" Pautas silenciadas e diálogos ausentes: uma análise fílmica de $\mathrm{O}$ dia de Jerusa. (Re) Existência Intelectual Negra e Ancestral: 18 anos de enfrentamento, 12 a 17 de 2018, Uberlândia, p.1-9.

VIEIRA, Luciana Oliveira. Autorrepresentação de cineastas negras no curta-metragem nacional contemporâneo. 2018. 138f. Dissertação (Mestrado Interdisciplinar em Cinema e Narrativas Sociais) Programa de Pós-Graduação Interdisciplinar em Cinema), Universidade Federal de Sergipe, São Cristóvão, 2018. 


\section{Obras apenas citadas}

hooks, bell. Yerning. Race, Gender and Cultural Politics. Boston: South End Press, 1990.

hooks, bell. Talking Black: Thinking Feminist, Talking Black. Boston: South End Press, 1898.

\section{Filmografia}

MULHERES negras: Projeto de Mundo. Direção de Dayane Rodrigues e Lucas Ogasawara. Santos; São Paulo: Dayane Rodrigues; Clicktac, 2016. 25 min.

SEMENTES: Mulheres pretas no poder. Direção de Éthel Oliveira e Júlia Mariano. Rio de Janeiro: Noix, 2020. $105 \mathrm{mim}$. 